УДК 821.I6I.I

ББК $83.3(2 \mathrm{Poc}=\mathrm{Pyc})+85$
ИЛЛЮСТРАТИВНЫЕ МАТЕРИАЛЫ

В БИОГРАФИЧЕСКИХ ИССЛЕДОВАНИЯХ

(ИЗ ОПЫТА ПОДГОТОВКИ «ЛЕТОПИСИ ЖИЗНИ И ТВОРЧЕСТВА С.А. ЕСЕНИНА»)

(C) 2017 г. М.В. Скороходов

Институт мировой литературы

им. А.М. Горького Российской академии наук,

Москва, Россия

Дата поступления статьи: І2 мая 2017 г.

Дата публикации: 25 сентября 2017 г.

DOI: IO.22455/2500-4247-20I7-2-3-334-345

Аннотация: Рассматриваются функции иллюстративных материалов в летописях жизни и творчества (деятельности). Детально характеризуется раздел «Приложение» «Летописи жизни и творчества С.А. Есенина» в 5 томах (7 книгах), включающий документальные и изобразительные материалы. Их широкое использование позволяет сделать биографическое исследование не только привлекательным для читателей, но и существенно дополнить сведения, содержащиеся в основной части Летописи.

Ключевые слова: биографические исследования, летопись жизни и творчества, биография С.А. Есенина, документальные источники, иллюстративные материалы.

Информация об авторе: Скороходов Максим Владимирович - кандидат филологических наук, старший научный сотрудник, Институт мировой литературы им. А.М. Горького Российской академии наук, ул. Поварская, д. 25 а, І2Іо69 Москва, Россия.

E-mail:msk2002@rambler.ru 


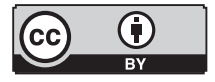

This is an open access article distributed under the Creative Commons Attribution 4.0 International (CC BY 4.O)

\section{ILLUSTRATIONS IN BIOGRAPHICAL}

STUDIES: SHARING EXPERIENCE OF

PREPARING THE CHRONICLE OF LIFE

AND WORK OF SERGEY ESENIN

(C) 20I7. M.V. Skorokhodov

A.M. Gorky Institute of World Literature

of the Russian Academy of Sciences, Moscow, Russia

Received: May I2, 2017

Date of publication: September 25, 2017

Abstract: The article discusses the function of illustrations in biographical studies. In particular, it examines a section "Appendix" in the 5-volume Chronicle of Life and Work of Sergey Esenin that includes documentary and visual materials. The use of illustrations not only makes a biographical study attractive to readers, but also serves as a welcome supplement to the information contained in the main part of the chronicle.

Keywords: biographical study, the chronicle of life and work, biography of Sergey Esenin, documentary sources, illustrations.

Information about the author: Maksim V. Skorokhodov, PhD in Philology, Senior Researcher, A.M. Gorky Institute of World Literature of the Russian Academy of Sciences, Povarskaya 25 a, I2I069 Moscow, Russia.

E-mail:msk2002@rambler.ru 
Для биографического исследования - научной биографии, творческой биографии, летописи жизни и творчества (деятельности) - важен иллюстративный ряд. Во многом это объясняется тем, что биографические исследования часто вводят в научный оборот значительный пласт новых материалов. Однако такие работы (за исключением материалов к биографии) не предполагают публикации изобразительных материалов и документов, в том числе архивных. Вместе с тем читателям, обращающимся к биографии известного человека, важно получить представление как о его жизни и деятельности, так и о восприятии его окружающими. Наконец - и это тоже немаловажно - читатели хотят иметь представление о внешнем облике главного героя исследования и его современников, именно поэтому необходимо воспроизведение изобразительных материалов - произведений живописи, графики, скульптуры, открыток и др.

В исследованиях биографического характера актуально представление не только биографии человека, которому посвящена работа, но частично и всей эпохи, в которую он жил и работал. Благодаря групповым фотографиям раскрывается круг общения главного героя. Иногда встречи, совместное участие в разного рода мероприятиях не находят отражения в текстовых документальных свидетельствах - анонсах и репортажах о прошедшем событии, письмах, дневниковых записях, мемуарной литературе, афишах и других источниках. Однако важные эпизоды личной и творческой биографии могут зафиксировать фотографы, причем совершенно не обязательно фотографы профессиональные.

Отметим, что иллюстративный ряд широко используется в различных справочных изданиях, в том числе энциклопедических - публикуются 
фотографии людей, которым посвящены биографические статьи, карты, отражающие содержание и этапы исторических событий, географических открытий. Приводятся всевозможные схемы, графики, диаграммы, облегчающие усвоение информации и дающие сжатое представление о том событии или явлении, которому посвящена энциклопедическая статья.

В летописях жизни и творчества (деятельности) как одном из научных биографических жанров использование иллюстративного материала, как правило, минимально. Этот вывод мы делаем на основе анализа многочисленных летописей, изданных в нашей стране и посвященных не только писателям, но и государственным деятелям, ученым, представителям сферы искусства. Очередной том может открывать портрет главного героя - часто этим иллюстративный ряд и ограничивается. Иногда может быть одна или несколько вкладок иллюстраций с фотографиями главного героя в разные периоды его жизни, портретами его родных и современников.

Например, первая книга «Летописи жизни и творчества Ф.И. Тютчева» открывается фотографией поэта $[7$, с. 2], а между летописной частью и «Приложениями» размещен не имеющий названия, не включенный в общую нумерацию и не обозначенный в содержании книги блок иллюстраций -26 страниц. Открывает подборку герб рода Тютчевых I802 г. Далее помещены портреты самого поэта, его родных и современников; рисунки и фотографии мест, в которых он бывал; обложки и страницы изданий, в которых печатался, автографы его произведений и иные материалы. В раздел «Приложения» [7, с. 277-304] входят две статьи научного руководителя и одного из составителей издания Т.Г. Динесман и статья другого составителя - С.А. Долгополовой.

Первый том «Летописи жизни и творчества Ф.М. Достоевского» открывается фотографией писателя [8, с. 2], а завершается семистраничной, расположенной в самом конце книги (после содержания, в которое данный раздел не включен) подборкой изобразительных материалов «Из собрания Литературного музея Пушкинского Дома» [8, с. 537-543].

Л.П. Гроссман, характеризуя особенности своей книги «Жизнь и труды Ф.М. Достоевского. Биография в датах и документах», отмечал: «В отличие от обычного типа <..> хронологических описей, мы включили в нашу работу ряд биографических документов, раскрывающих читателю глухое и беглое календарное указание и непосредственно вводящих его в 
историю жизни Достоевского. Ряд официальных актов, писем, статей, дипломов, счетов, договоров и контрактов, приведенных полностью в тексте настоящей работы, непосредственно обращает нас от сводки дат к биографии писателя» [2, с. 7]. В книге «воспроизведены наиболее значительные изображения Достоевского, причем иконография самого писателя дополнена иллюстративным материалом, относящимся к его современникам, родственникам, друзьям, местам его пребывания, документам его творческой истории - рукописям, рисункам, снимкам с различных изданий и пр.» [2, с. 9]. В небольшом, объемом четыре страницы, «Приложении» к «Летописи жизни и деятельности Н.А. Добролюбова» С.А. Рейсера [9] помещена родословная таблица и приведены некоторые другие материалы.

Для биографических изданий, посвященных С.А. Есенину, характерно внимание к документальному и иллюстративному материалу. В работе В.Г. Белоусова [I] наряду с основным разделом - «Литературная хроника» - имеются разделы «Дополнения» (комментарии к летописным статьям и дополнения их документальными источниками, обоснование датировок и др.) и «Иллюстрации» (воспроизведение фотографий Есенина, в том числе коллективных, автографов его произведений, заполненных им анкет, документов личного происхождения). Большое число иллюстраций - фотографий, рисунков, автографов и др. - включено в подготовленную С.И. Субботиным, Н.И. Гусевой (Н.И. Шубниковой-Гусевой) и С.В. Шумихиным книгу «С.А. Есенин. Материалы к биографии» [Іо].

При обсуждении концепции и структуры «Летописи жизни и творчества С.А. Есенина» инициатором создания этого труда и главным редактором первых двух томов Ю.Л. Прокушевым был поставлен вопрос о включении в Летопись раздела, который получил название «Приложение», - блока текстовых документов и иллюстраций. В период подготовки томов Летописи выяснилось, что этот раздел должен быть весьма объемным и нести значительную нагрузку в плане не только иллюстрирования, но и введения в научный оборот большого массива новых материалов.

В первом томе Летописи отмечено, что в состав «Приложения» входят «полностью те важнейшие новые документальные материалы, цитаты из которых фигурируют в основном тексте “Летописи...”. В “Приложение” включены фото- и ксерокопии наиболее характерных материалов, связанных с конкретными летописными статьями: автографы ряда стихотворе- 
ний, писем, дарственных надписей, журнальных публикаций произведений Есенина, обложки его книг, ряд документов, касающихся биографии поэта. Кроме этого, “Приложение” знакомит с портретами поэта, его родных и близких, друзей детства и юности, поэтов, писателей, издателей, с которыми встречался Есенин, <включает> фотографии памятных мест, связанных с жизнью поэта» [4, с. 73].

Определенная в «Предисловии к первому тому» структура «Приложения» характерна для всех томов «Летописи жизни и творчества С.А. Есенина». К материалам этого раздела имеются отсылки в основном тексте - после конкретных летописных статей. Таким образом, у читателя появляется возможность получить дополнительную информацию, расширяющую сведения, содержащиеся в той или иной летописной статье. «Приложение» раскрывает контекст эпохи, творческие и личные взаимоотношения Есенина с современниками.

В «Приложении» материал выстроен по местам пребывания поэта, а внутри каждого подраздела - по хронологии. В первом томе подразделы открывают видовые фотографии - пейзажи родного есенинского Константинова, села Спас-Клепики, в котором начинающий поэт учился во второклассной школе, виды Москвы, Петрограда, Царского Села. Эти материалы помогают читателю Летописи представить те реалии, которые были важны для поэта. Во втором томе, в котором материалы «Приложения» разделены на три подраздела - «Царское Село. г9І7», «Петроград. І9І7-г918», «Москва. I918-I920», - широко используются открытки начала XX в. Например, «Общий вид Царского Села», «Москва. Тверская улица», «Москва. Страстная площадь» $[5$, с. 463, 544, 545]. В следующих томах Летописи «Приложение» не делится на подразделы в соответствии с местами пребывания Есенина, что обусловлено его активными перемещениями в I92I-I925 гг. При этом во всех томах место нахождения Есенина обозначено в колонтитуле - это относится как к основному летописному тексту, так и к «Приложению».

Для исследователей творчества Есенина особую значимость имеют автографы. В «Приложении» представлены как черновые с многочисленными слоями правки, так и беловые автографы. В качестве иллюстративного материала приводятся адресованные современникам дарственные надписи поэта на книгах. 
$\mathrm{B}$ «Приложении» к первому тому по архивным источникам печатаются формулярные списки лиц, оказавших значительное влияние на формирование Есенина в детском и юношеском возрасте. Это отец Иоанн (Смирнов) - священник церкви Казанской иконы Божией Матери, законоучитель Константиновского земского училища, в доме которого Есенин проводил многие часы, беседуя или читая книги и журналы, Е.М. Хитров - первый литературный наставник начинающего поэта, преподаватель Спас-Клепиковской второклассной учительской школы и некоторые др. Информация о школьных учителях Есенина введена в Летопись в связи с тем, что ранее она нигде не публиковалась. Естественно, что биографические данные о более известных современниках поэта в «Приложение» не включены. При этом иллюстративные материалы, характеризующие деятельность таких людей, входивших в круг общения Есенина, широко представлены в «Приложении»: публикуются их фотографии, графические изображения, включая шаржи, воспроизведены обращенные к Есенину дарственные надписи, адресованные ему письма.

В Летописи, как и в персональных энциклопедиях, наблюдается интересная закономерность: чем известнее человек, тем меньший объем биографических сведений о нем приводится. Так, в «Лермонтовской энциклопедии» не объясняется, кто такой Пушкин, Гоголь или Блок. По этому пути пошли и составители есенинской Летописи. В тех случаях, когда информацию о человеке сложно получить из других источников, в летописных статьях характеризуется сфера его деятельности, а в «Приложении» приводятся документы, раскрывающие факты его биографии. Во вторую книгу пятого тома Летописи включен аннотированный указатель имен и названий, в котором характеризуется сфера деятельности и даты жизни каждого упоминаемого в Летописи лица.

В качестве иллюстраций в «Приложение» включены наиболее показательные и значимые печатные материалы, характеризующие восприятие есенинского творчества современниками. Приоритет отдается малоизвестным или впервые вводимым в научный оборот источникам. Если газеты, журналы и книги, вышедшие около столетия назад, можно прочитать в некоторых библиотеках (часть из них доступна теперь и в электронном виде), то, например, афиши и программы литературных вечеров до недавнего времени были практически недоступны. Вместе с тем эти документы раскрыва- 
ют круг общения, творческие контакты поэта. В афишах и программах перечисляются члены литературных групп - как соратники, так и литературные оппоненты Есенина. Отметим, что раздел «Афиши и программы вечеров» был включен в Полное собрание сочинений поэта, он находится в конце собрания - завершает вторую книгу седьмого тома. Такое расположение обусловлено тем, что «прямых сведений о непосредственном участии поэта в составлении большинства афиш не обнаружено». Однако «отсутствуют какие бы то ни было данные, что имя Есенина появилось на той или иной афише без его ведома. К тому же известно, что при подготовке вечеров, организуемых Всероссийским союзом поэтов (ВСП), составлением афиш и их публикацией занималась специально избираемая из числа членов ВСП “программная комиссия”, которая рассматривала заявки поэтов на участие в литературных мероприятиях <...> на афишу ВСП имя Есенина могло попасть лишь при наличии его заявки, то есть по его собственному желанию» [3, с. 566]. Если в Полном собрании сочинений воспроизводятся тексты афиш и программ, сопровождаемые необходимыми комментариями, то в Летописи некоторые документы даются в качестве иллюстративного материала. Например, афиша и программа первого вечера искусств литературно-художественного общества «Страда», состоявшегося I9 ноября I9I5 г. [4, с. 66о-662], недельные афиши выступлений поэтов на эстраде-столовой ВСП [5, с. 591, 602, 609, 626, 633, 637, 649, 650], афиша выступления имажинистов в Политехническом музее 3 апреля І9І9 г. [5, с. 6І4], афиши поэтических вечеров в Политехническом музее [5, с. 697, 713].

Отметим, что благодаря размещению в открытом доступе Государственного каталога Музейного фонда Российской Федерации (в данный момент далеко не все музейные предметы и коллекции оцифрованы и представлены в сети Интернет) появилась возможность поиска в этой базе данных как афиш, так и других иллюстративных материалов. Так, благодаря этому ресурсу при подготовке второй книги пятого тома Летописи нами была обнаружена афиша вечера памяти Есенина, прошедшего в Ленинграде 8 февраля 1926 г., из собрания Государственного литературно-мемориального музея Анны Ахматовой в Фонтанном Доме (в базе данных этот документ ошибочно отнесен к г927 г.).

Значительное место в «Приложении» занимают обложки книг Есенина, его современников, коллективных сборников с участием поэта, по- 
священных ему изданий, а также журналов. Обложка многое говорит об эпохе. Над некоторыми из них работали известные художники. На обложках журналов часто обозначены темы, актуальные для своего времени. По обложке можно определить, на какую группу читателей ориентировано издание, какие вопросы являются для него приоритетными. В «Приложении» в ряде случаев помещены титульные листы, а также содержание, в котором обозначены публикации произведений Есенина и посвященных ему работ. Порой в качестве иллюстраций, раскрывающих историко-литературный контекст, воспроизводятся страницы с перечнями печатавшихся в том или ином издании авторов. Приводятся редкие документы - например, «Положение о церковных школах ведомства православного исповедания» (воспроизведены страницы еженедельника «Церковные ведомости») - в соответствии с этими правилами не только составлялась программа обучения, но и строились школьные здания. Публикуются выдержки из учебных планов и программ Спас-Клепиковской второклассной учительской школы и Московского городского народного университета имени А.Л. Шанявского. Расписание занятий этого учебного заведения позволяет установить, в какие часы и дни читались те или иные лекционные курсы. Приводится фрагмент устава литературно-художественного общества «Страда», в деятельности которого молодой поэт принимал непосредственное участие.

Здания, которые посещал поэт, - это места, связанные с памятью о нем. Далеко не все они сохранились до наших дней. Многие утрачены, другие перестроены. При публикации предпочтение отдается фотографиям прижизненным или близким по времени к периоду нахождения поэта в населенном пункте. Так, в «Приложении» ко второй книге третьего тома Летописи, посвященной периоду заграничной поездки, публикуются фотографии мест пребывания поэта. В их числе редкие снимки гостиниц, в которых проживал Есенин вместе с А. Дункан, І924 г. [6, с. 447-448] из собрания английского слависта Г. Маквея (недавно вся коллекция этого ученого передана им в дар Государственному музею-заповеднику С.А. Есенина). В ряде случаев, когда известно, что здание избежало значительной перестройки, приводятся фотографии, сделанные в наше время.

Важная группа материалов - зарубежные источники. До подготовки «Летописи жизни и творчества С.А. Есенина» прижизненные публикации стихотворений поэта на иностранных языках и статей о нем в зарубежной 
периодике были введены в научный оборот в крайне ограниченном объеме. При подготовке томов Летописи выявлен значительный пласт новых материалов, их фрагменты представлены в «Приложении». Отметим, что в основном корпусе Летописи содержится предельно краткая информация: о выходе сборников, включающих произведения Есенина, небольшие цитаты из статей критиков и сопроводительных текстов переводчиков. В «Приложении» же даются целые газетные или журнальные полосы. Это позволяет проанализировать, в каком контексте публиковались есенинские тексты и материалы о нем.

Структура раздела «Приложение» в разных томах однотипна, однако имеются отдельные различия. Так, в завершающую издание вторую книгу пятого тома вошли разделы, включающие посмертные (появившиеся в течение полугода после гибели) материалы - о похоронах, вечерах памяти, публикации произведений Есенина, материалов о нем и др., - соответствующие документы и иллюстрации войдут в «Приложение». В последнюю книгу издания войдет и специальный указатель материалов, включенных в «Приложение», который позволит ориентироваться во всем многообразии вошедших в него материалов.

Опыт «Летописи жизни и творчества С.А. Есенина» свидетельствует о том, что широкое использование иллюстративного материала позволяет сделать биографическое исследование не только привлекательным для читателей, но и существенно дополнить данные, содержащиеся в основной части Летописи. Иллюстративный ряд книги, как и музейная экспозиция, адресован разным целевым группам. Одни заинтересуются «картинками», другие будут сопоставлять приведенные документы и материалы с уже известными им, а третьи используют сведения, полученные при знакомстве с иллюстративным рядом, для собственных научных разработок. 


\section{Список литературы}

I Белоусов В.Г. Сергей Есенин. Литературная хроника: в 2 ч. М.: Сов. Россия, 1969-I970. 304 с. +448 c.

2 Гроссман Л.Н. Жизнь и труды Ф.М. Достоевского. Биография в датах и документах. М.; Л.: Academia, I935. 386 c.

3 Есенин С.А. Полн. собр. соч.: в 7 т. М.: Наука; Голос, 2о0о. Т. 7. Кн. 2. 640 с.

4 Летопись жизни и творчества С.А. Есенина: в 5 т. М.: ИМЛИ РАН, 2003. Т. І. $736 \mathrm{c.}$

5 Летопись жизни и творчества С.А. Есенина. М.: ИМЛИ РАН, 2005. Т. 2. 760 с.

6 Летопись жизни и творчества С.А. Есенина. М.: ИМЛИ РАН, 2008. Т. 3. Кн. 2. $575 \mathrm{c}$.

7 Летопись жизни и творчества Ф.И. Тютчева. Кн. первая. І803-І844. М.: Литограф, I999. 34I с.

8 Летопись жизни и творчества Ф.М. Достоевского: в 3 т. СПб.: Академический проект, І993. Т. І. 544 с.

9 Рейсер С.А. Летопись жизни и деятельности Н.А. Добролюбова. М.: Гос. изд-во культ.-просвет. работы, І953. 370 с.

Iо С.А. Есенин. Материалы к биографии. М.: Историч. наследие, I993. 448 c. 


\section{References}

I Belousov V.G. Sergei Esenin. Literaturnaia khronika: $v 2$ ch. [Sergey Esenin: Literary chronicle in 2 vol.]. Moscow, Sov. Rossiia Publ., I969-1970. 304 p. + 448 p. (In Russ.)

2 Grossman L.N. Zhizn' i trudy F.M. Dostoevskogo. Biografiia v datakh i dokumentakh [Life and works of Fyodor Dostoevsky. Biographical facts and materials]. Moscow, Leningrad, Academia Publ., I935. 386 p. (In Russ.)

3 Esenin S.A. Polnoe sobranie sochinenii: $v 7 t$. [Complete collection of works: in 7 vol.]. Moscow, Nauka; Golos Publ., 2000. Vol. 7. Book 2. 640 p. (In Russ.)

4 Letopis' zhizni i tvorchestva S.A. Esenina: $v 5 t$. [The chronicle of Life and Work of Sergey Esenin: in 5 vol.]. Moscow, IWL RAS Publ., 2003. Vol. I. 736 p. (In Russ.)

5 Letopis' zhizni i tvorchestva S.A. Esenina [The chronicle of life and work of Sergey Esenin]. Moscow, IWL RAS Publ., 2005. Vol. 2. 760 p. (In Russ.)

6 Letopis' zhizni i tvorchestva S.A. Esenina [The chronicle of life and work of Sergey Esenin]. Moscow, IWL RAS Publ., 2008. Vol. 3. Book 2. 575 p. (In Russ.)

7 Letopis' zhizni i tvorchestva F.I. Tiutcheva. Kn. pervaia. I803-I844 [The chronicle of life and work of Fyodor Tyutchev]. Moscow, Litograf Publ., I999. 34I p. (In Russ.)

8 Letopis' zhizni i tvorchestva F.M. Dostoevskogo: $v_{3} t$. [The chronicle of life and work of Fyodor Dostoevsky: in 3 vols.]. St. Petersburg, Akademicheskii proekt Publ., I993. Vol. I. 544 p. (In Russ.)

9 Reiser S.A. Letopis' zhizni i deiatel'nosti N.A. Dobroliubova [The chronicle of life and activities of Nikolay Dobroliubov]. Moscow, Gos. izd-vo kul't.- prosvet. raboty Publ., I953. 370 p. (In Russ.)

Io S.A. Esenin. Materialy k biografii [Sergey Esenin. Biographical materials]. Moscow, Istorich. nasledie Publ., I993. 448 p. (In Russ.) 